NATURE to know that in January I88I I captured a single specimen of Peripatus in the low, damp woods at Breves, on the island of Marajo, mouth of the Amazon. The specimen is now in the entomological collections of Cornell University, Ithaca, N.Y. Bloomington, Ind., U.S.A., September 2 UN C. BRANNER

\section{THE RECENT EARTHQUAKE IN GREECE}

I FORWARD the inclosed copy of a report made by 1 the master of the steamship La Valette in reference to the earthquake which occurred in Greece last month, in case you may not have received the report and might wish to publish it.

\section{Admiralty, September 20}

\section{W. J. L. WhaRTon, Hydrographer}

Report made by the Master of the s.s. "La Valette" to the Superintendent of the Ports, Malta, furnishing certain particulars in connection with the earthquake which occurred on August 27

On the 27th inst., at II.30 p.m., whilst in lat. $36^{\circ} 18^{\prime} \mathrm{N}$. and in long. $21^{\circ} 32^{\prime} \mathrm{E}$., or at a distance of 50 miles W. $\frac{1}{2}$ S. from Cape Matapan, I felt, all of a sudden, a very strong shock, which made the ship tremble, especially the engines, for the space of about II seconds. The ship was proceeding at the rate of 10 knots an hour, and with such shaking lost her course. The engineer thought that the screw had been lost. After the shaking was over all was right again. At midnight in the direction west-north-west, in lat. $36^{\circ} 17^{\prime} \mathrm{N}$., long. $21^{\circ} 27^{\prime}$ E., I observed on our right something like a mass of thick black smoke, which, like a cone, was rising up perpendicularly from the horizon, and at intervals changing into a reddish colour. In the meanwhile a perfect calm prevailed, with heavy sea from west at intervals. At 4 a.m. of the 28 th, when the ship was in lat. $36^{\circ}$ $12^{\prime} \mathrm{N}$., and in long. $20^{\circ} 43^{\prime}$ E., the wind commenced blowing from north-west, which made the horizon a little clear. At ro a.m. the mate, who was on watch on the bridge, reported to me that he had observed in the sea several stripes of a dark yellowish colour about one quarter of a mile long in the direction from north to south, which looked like shallows. The sea continued always heavy from west with very little wind. As the ship had a cargo of cattle, which suffer greatly from heat, I could not lose time in measuring the depth of the aforesaid stripes; therefore I tried to avoid them. During the navigation I thought proper to take precautions, as when I was at Alexandretta my owners informed me by telegraph of the report made by Capt. Tomlinson, of the steamer Transition.

Malta, August 29, 1886

$$
\text { (Signed) CAPT. L. Aquilina }
$$

\section{THE TOTAL SOLAR ECLIPSE OF $\mathrm{I} 886$}

$\mathrm{W}$

E suppose that if, some months ago now, when the question of sending out an Expedition to Grenada during the rainy season was first discussed, any one had prophesied that out of a party of eight seven would see the eclipse and record results, the general feeling would have been that such a view would have been too sanguine. This, however, is what has happened, and so far as the securing of observations and photographs goes the Expedition must be pronounced a success.

With regard to the total result, however, no one is yet in a position to speak with certainty, for some of the photographs taken are not yet developed, and others, though developed, have not been submitted to any examination. On this point, however, we need not lay any great stress, for such photographs, though invaluable as records, do not help yet so much as such pictures will certainly be made to do hereafter in the matter of solar theory, for the reason that they are not large enough and not detailed enough.

Has, then, solar theory been advanced by the eye observations? From the sketch of the work done which appeared in yesterday's Times, from the pen of a Correspondent in Grenada, and which we reproduce, we think it has certainly. Prof. Tacchini's observation that the prominences seen most prominently during the eclipse were not the prominences seen by the ordinary method, and that the latter only reveals part of a very complicated phenomenon, is valuable in itself, but taken in connection with the fact that the eclipse prominences and the parts of the prominences not seen by the ordinary method are probably downrushes, wholly or partially, it is difficult to overrate its importance. These eclipse prominences, which Prof. Tacchini calls "white" prominences, are high and filamentous, and that distinguished observer, we know, does not hesitate to express his belief that the "comet" seen in the eclipse of 1882 was really one of them. If this be so, then the meteoric downpours of consolidating and consolidated materials are already en évidence with a vengeance, and these are the parts of the solar economy we want most to lay hold of just now.

That part of the Times Correspondent's letter which refers to the results obtained runs as follows:--

"The Green Island party was the only one doomed to disappointment. At Carriacou, Boulogne, Hog (or Fantôme) Island, and Prickly Point the eclipse was seen and results secured, although at these places even it was touch and go, the sky being cloudy everywhere. Carriacou was most highly favoured. During the totality the sky was cloudless, though the sun was covered one minute after the rim re-appeared. At Fantôme Island the last 40 seconds, and at Prickly Point the first 50 seconds, were lost. At Boulogne the clouds were still more persistent, and cut off 70 seconds of the totality, although Mr. T'urner secured some observations during the four minutes before and the five minutes after. The presence of cloud during totality is a more serious matter than it might appear at first sight, for not only is the time reduced during which precious facts may be recorded, but pre-arranged programmes are interfered with, and it may be necessary to change them in order to meet the altered conditions. This requires a rapid and wise decision.

"Before I attempt to give any summary of the general results obtained, it may be remarked that the kinds of work attempted as a rule by eclipse expeditions are four in number, and are very distinct both in their methods and results from each other. We have first of all new facts, or new views of facts, which experience shows us are always obtained at such times, though they are not sought for as such. Next comes the testing of views which have bejen put forward to explain and harmonise the results previously obtained, and this part of the attack becomes very important when there are rival hypotheses in the field, the superiority of one of which can be established by a few critical observations. The third kind of work is the testing of the new methods of obtaining facts, the introduction of new instruments, or of new or improved ways of using old ones. Only in this way can a complete and perfect system of eclipse observation be built up. Finally we have the application of the ordinary methods of obtaining records, which for the most part are photographic. Astronomers not only want to study the phenomena of each eclipse to get at the physical and chemical structure and nature of the sun's atmosphere, but they want to note the changes from eclipse to eclipse, in order to see which phenomena are liable to variation, and the extent and period of such variation if it exists.

"Now in the eclipse observations secured in Grenada and Carriacou a distinct advance has been made along all the four lines to which reference has been made. New 
facts have been acquired, old views have been satisfactorily tested, new instrumental methods have been studied, and records of the general phenomena have been secured. I will as briefly as possible go over each of these points in turn.

"First as to the new facts. For these we have to refer to the work of Prof. Tacchini at Boulogne. No one was more competent than he to note the prominences and other appearances visible during the eclipse. This he did with a 6-inch, and so soon as the clouds permitted after the eclipse he observed the spectrum of the prominences by the ordinary method. He found that the prominences seen under these two different conditions and by means of such different methods were not the same. He also noted that the prominences seen during the eclipse itself had the same characters as the so-called 'white' prominences which he observed in 1883 at the Caroline Islands. These appear whiter and dimmer as the distance from the photosphere increases. These observations have been very closely examined by Prof. Tacchini and Mr. Lockyer, with the result that both these solar observers are now prepared to ascribe these new phenomena to the descent of relatively cool material.

"It is difficult to over-estimate the importance of this result from the point of view of solar theory. The determination of the direction of the currents in the solar atmosphere is indeed so important that it was included in the programme of the observations to be made by $\mathrm{Mr}$. Turner with his 4 -inch finder, but no certain results were secured by this means, as the structure of the corona was apparently unusually complicated. In the spectroscope, however, one long streamer was observed to be much brighter near the limb. This is not absolutely conclusive evidence, but it has its value.

"To return, however, to Prof. Tacchini's other observations. He found that the prominences which were visible both during totality and by the ordinary method presented very different appearances, so that we are driven to the conclusion that by the latter we only see part of the phenomena. This entirely accords with $\mathrm{Mr}$. Lockyer's recently published views, in which it is suggested that the metallic prominences seen near spots are really mixed up and down rushes, with probably an excess of the cooler descending material. Thus, for instance, the metallic prominences observed by the ordinary method after, the eclipse were found to be only the central portions of those obscrved during totality, the part visible only during totality forming a whitish fixise round the more incardescent centre. Another very important observation was made. 'The 'flash' of bright lines, attributed by Prof. Young to the existence of a thin stratum which was supposed to contain all the vapours the absorption of which is registered by the Fraunhofer lines, was found to be due solely to the great reduction in the intensity of the light reflected by the earth's atmosphere allowing the spectrum of the higher regions to be seen the moment the lowest stratum of the corona was covered by the moon. This is carrying the unveiling of the spectral effects by the increasing darkness recorded in the Egyptian eclipse to its furthest limit, and it harmonises all the observations of this kind made since the eclipse of 1870 .

"So much in the way of new facts and new ideas. We next come to the second kind of work, the testing of old ones. In this connection we have to refer to Mr. Turner's work at Boulogne and Mr. Perry's at Carriacou. Mr. Lockyer, before the eclipse of $\mathrm{i} 882$, had been driven by a long series of experiments and observations to conclude that the lower part of the atmosphere was composed of successive strata giving different spectra, and that the sole cause of the difference was temperature. A test was possible during an eclipse, for then these lines of any substance seen to brighten when a higher temperature is employed in the laboratory should be seen shortest and brightest. The test was perfectly sharp and definite. It was applied during the eclipse of 1882, and the lines appeared as predicted.

"So far, then, the hypothesis which had enabled a prediction to be made which was subsequently verified was worthy of confidence. But this was a reason for repeating the observations to put the hypothesis on a wider basis. Mr. Turner did this, and found that the facts observed this year were the same as those recorded in 1882 . It remains now for those who oppose Mr. Lockyer's views to give a more simple and sufficient explanation of those facts than he has done. Mr. Perry was to have extended the test further, but he failed to make the critical observation, as a large number of lines were seen, and those only for a short time, for the clouds came up directly after totality.

"Capt. Darwin was charged with a test of a different order. It was stated, after the eclipse of $187 \mathrm{I}$, that the light of the corona was in all probability strongly photographic; and in 1875 the evidence in this direction was greatly strengthened, and some attempts were made to utilise this quality to obtain photographs of the corona without an eclipse. The efforts failed. More recently Mr. Huggins has tried the same methods with great precautions, and he has obtained appearances on his plates which resembled the corona, so that some thought that success had been achieved. The natural thing to do was to test the method during the progress of the eclipse to see if the appearances in question, due to atmospheric glare according to some, to the corona according to others, really resembled the corona when revealed by totality. Capt. Darwin's work seems to leave no doubt that the effect is due to glare only, and that the corona has nothing to do with it.

"Next as to new methods of attack. This year the only new method applied has been a change of the photographic manipulator, with a view of obtaining a much larger number of photographs and increasing the size of the images at the same time, by using larger lenses of longer focus and secondary magnifiers. Along this line success has not been complete, because the photographs have not been actually taken, as this new work was undertaken by Mr. Lockyer and his party at Green Island, and was clouded out. In spite, however, of this want of photographs, Mr. Lockyer will net hear of want of success. He holds that the problem has been solved.

"I have given an account of the work at Green Island, including the results of the rehearsals, and your readers will have been able in a large measure to form an opinion of their own. The improvement consists essentially in using four plates in one slide. The difficulty always has been in getting the slide in and out of position, so that the more plates we can work in one slide the more the difficulty and consequent loss of time are evaded. Another advantage lies in the use of a secondary magnifier, as by this means not only is the photographic image of the sun enlarged, but a system of cross wires can be introduced which permits of a perfect orientation of the picture obtained - that is, the exact east and west points on the circumference can be determined with the utmost precision, and from this the position of the various phenomena with regard to the sun's equator and poles. It can be easily imagined that on this point there must be no uncertain sound.

"We next come to the photographic record obtained by old methods-that is, methods dating in the case of photography of the corona from 1852 , and in the case of spectrum photography from 1875 . About twenty photographs of the corona have been obtained in all, and five photographs of the chromosphere and lower regions of the corona. Mr. Maunder obtained seven of the corona, and cuuld have obtained more, at Carriacou. Captain Darwin obtained six, and Dr. Schuster, we believe, five, at Prickly Point. Of the photographs seven spectra, two with the 
solar spectrum on the same plate-the only ones worth anything, have also been secured by Mr. Maunder. But we must not build too much on this, for, as I have said before, these photographs have not yet been developed; but if only one good one has been received, the laboratory work it should set going will take at least one or two years before the teachings of the precious record are exhausted. The so-called 'measurement' of such photographs is worth next to nothing.

"Among the records obtained on this occasion must be classed the disk observations, now for the first time included in the ordinary routine of eclipse work. The point of a disk observation is that an observer is by its aid able to observe the outlying solar appendages under the best conditions, so far as the sensitiveness of the eve is concerned. For ten minutes before totality the observer is blindfolded, and at the moment of the totality he is led to a small aperture through which, the bandage over his eyes having been removed, he sees a black disk some 40 feet away, which shuts off the moon and the brighter interior portion of the solar atmosphere. The eye, therefore, being thus shielded, is in the best position to pick up faint streamers extending beyond the borders of the disk, and to note their positions and extension. Streamers were thus noted at Grenada, extending far beyond the limits seen in the ordinary way, but the air was so saturated with aqueous vapour and incipient cloud, even where substantial clouds did not make their appearance, that the failure of any of the observers to see the equatorial extension observed by Prof. Newcomb in the clear sky of Wyoming, at an elevation of 7000 feet, in 1878 , by no means proves that the extension was not there. The question of the continual existence of an extension of matter of some sort or other in the plane of the sun's equator must be held to be still sub judice.

"Capt. Archer at Fantôme Island, and Capt. Maling at Prickly Point, made disk observations fairly accordant. The former had greatly improved the disk provided him by surrounding it with concentric rings of wire, so that distances from the centre could be measured with the greatest accuracy.

"The records obtained by Prof. Thorpe regarding the intensity of the light of the corona were sufficient in number to suggest that when they are reduced a value will be obtained to be placed side by side for purposes of comparison with those previously obtained in 1870 and 1878 . In this connection it may be remarked that the darkness of an eclipse must not be taken as a measure of the dimness of the corona, for, if the totality be longer, more of the brighter portion of the solar atmosphere will be covered. This was certainly the darkest eclipse seen since eclipse expeditions have been in vogue. This shows the importance of Prof. Thorpe's work, for if successful it will give us the luminous intensity per unit of surface of different regions of the solar atmosphere, as well as the intensity of the total light emitted.

"The preceding sketch of the results obtained has of necessity been of the most general character. Not till all the observations are published in detail, as they doubtless will be at no very distant date by the Royal Society, and not till they have been discussed by those competent to discuss them, can a final verdict as to their value be given. We have of set purpose dealt only with the conclusions which lie on the surface."

\section{NOTES}

THE death of Alessandro Dorna, Director of the Astronomical Observatory of Turin, took place on August 19 last, at the age of sixty-one years.

THE annual Congress of the Sanitary Institute of Great Britain commenced on Tuesday in York. Sir T. Spencer Wells, the President, commenced his inaugural address by expressing the hesitancy with which he accepted the position of President of the Congress, a hesitancy induced by the knowledge that he could not presume to appear before a body of sanitary experts as an instructor. Having referred to questions which had been dealt with in regard to sanitary science by his predecessors in the Presidential chair, he observed that it now remained to be considered how sanitary improvements might be carried still further by the co-operation of investigators, legislators, and administrators. As to the work of investigation, it had hitherto for the most part been personal, and the waste of labour had been enormous. The Institute must develop into something grander and more powerful. The Colleges of Physicians and Surgeons had done much, but it was rather for individual than collective good. Why should we not have a College of Health ? The President then reviewed the work which those whom he called the "advanced guard of sanitary science" had accomplished, in lessening the death-rates of our population, and in benefiting the public health by prolonging life. Much of this he attributed to the coincident progress made in the science and art of medicine and surgery. He claimed for the medical profession a considerable share in the gain to the State of increasing numbers of more healthy subjects. We could not be far wrong if we put the average duration of human life in Great Britain half a century ago at about thirty years ; now, according to the healthy life table, it was forty-nine years. Formerly it was calculated that a twenty-third part of the population was constantly sick, and the products of all that labour for the time necessarily withdrawn. A great deal of this sickness had been altogether prevented, and the duration of that which comes in spite of sanitation was lessened. He then dealt with the progress which had been made, since the Sanitary Institute had come into existence, in the moral and physiral condition of our population. Dealing then with the various subjects to which the Institute had given attention, he divided them into five groups: (I) those relating to the training and health of the population; (2) to their social comfort and well-being; (3) to the prevention of disease; (4) to the care of the sick; and, lastly, those relating to the disposal of human refuse and remains. As to teaching the public on sanitary matter; it could never be done without elaborate organisation and legislative authority.

ONE of the tasks undertaken by the authorities of the British Museum since printing has taken the place of handwriting in the Catalogue is the publication of certain important sections of the Catalogue in separate parts. Thus the entries under America, Cicero, Luther, London, and many others have already appeared. The last of these is one of special scientific interest: it is a reprint of that part of the Catalogue which is classified under the head Academies. The definition of academies, for the purpose is "Learned and Scientific Societies." The entries fill five parts, making a thick folio volume of about one thousand pages. In the great written Catalogue, which is well known to all readers, twenty-eight volumes were given to this one subject. The headings have been thoroughly revised throughout, and the names of a number of societies have been expunged, to be placed under more appropriate headings. Thus, agricultural societies, schools, political clubs, \&c., which had crept into the Catalogue by degrees in course of time, have all been omitted. As it is, the total number of entries is about 32,000 . "London" is the longest sub-heading; it fills nearly 200 pages, with about 6500 entries. Paris, St. Petersburg, and Berlin have about 3000 entries each; Vienna and Amsterdam about 1000. Towns are used for sub-headings, and under these are arranged alphabetically the names of the societies issuing the publications. The old sub-headings of countries have been abolished. Formerly the sub-hexling; wo sld read thus:- 